\title{
Ecological briquettes from sunflower seed husk
}

\author{
Cosmin Spirchez ${ }^{1}$, Aurel Lunguleasa ${ }^{1}$, and Cătălin Croitoru ${ }^{2}$ \\ ${ }^{1}$ Transilvania University of Brasov, Wood Processing and Design Wooden Product Department, 29 Street Eroilor, Brasov, Romania \\ ${ }^{2}$ Transilvania University of Brasov, Engineering Materials Department, 29 Street Eroilor, Brasov, Romania
}

\begin{abstract}
The paper aims to use the waste of sun-flower hulls in order to obtain some lignocellulosic briquettes as renewable solid fuels. First, the sunflower seed husks were ground, after that they were sorted and only the fractions corresponding to the briquettes and pellets were used. After obtaining the stable briquettes there were determined the physical and caloric properties of briquettes manufactured from sunflower husks, as potential alternative biofuels. The moisture content, ash content and density of the briquettes have been determined and correlated with their calorific properties, namely the calorific value and calorific density. The experimental results have indicated that, even if the self-adhesion of sunflower seed hulls is less than that of wood sawdust, they have a better behaviour in humid environment. Good results make it possible to use these briquettes for both household heating systems and thermal power plants.
\end{abstract}

\section{Introduction}

Nowadays there is an impinging potential crisis of fossil fuels, as research shows a shortage for oil and coal in the next $50-60$ years [1,2]. Wood that traditionally was used as energy source since ancient times is currently under regulation, as most of countries from the European Union are concerned with the preserving of the natural forest biotopes [2]. Due to these regulations imposed at national level, even inferior quality wood (obtained from branches and boughs), becomes less available $[3,4]$.

Biomass is a renewable energetic source, because it increases from one year to another, it is widely spread world-wide and presents low costs in comparison to the fossil fuels, the biomass resources, from which fuel material is produced may include wood and wooden wastes, agricultural cereals and wastes resulted from their production, aquatic biomass and algae $[12,15]$.

Wood industry by-products, such as sawdust, have been successfully used for the manufacturing of briquettes with satisfactory caloric properties, but nowadays a great deal of attention are focused on other type of biomass-derived materials, such as fruit seeds, peels and so forth [3-8].

By appropriately modifying the properties of these biomass-derived materials, for example by thermal treatment, they could be transformed in superior fuels such as briquettes and pellets.

Oleaginous seed husks have attracted attention lately due to their generation as byproduct in considerable amounts in the oil production industry [9] and to their potential use as high caloric-output materials, aided by the trace amounts of fatty polyesters.

A sun-flower seeds processing unit has a current capacity of 400 tons in 24 hours, from which it results approximately 100 tons of seed shelling.
Although the sun-flower seed shelling are wastes of the main production process (Fig 1), it is necessary to manage them, because they can lead to blockages in the storage facility of the factories.

The main uses of sunflower seed shelling are in the briquettes and pellets field, and in the lignocellulose composites. They are reported to combust with minimal emissions of volatile organic compounds in the atmosphere, thus making them useful as an alternative ecologic fuel.



Fig. 1. Sunflower oil production flow

\section{Materials and methods}

For determining the effective density of the briquettes, 12 pieces of pellets have been chosen and machined to 
obtain regular cylindrical specimens, usually by sanding ends with disc machine. The effective density is usually determined as a ratio between mass and volume. The relation in Eq.1 (considering the cylindrical form of briquettes) had been used in order to obtain effective density of briquettes:

$$
\rho_{e f}=\frac{4 m}{\pi \cdot d^{2} \cdot l}\left(\mathrm{~g} / \mathrm{cm}^{3}\right)
$$

Where:

$\mathrm{m}$ is mass of briquettes, in $\mathrm{g}$;

$\mathrm{d}$ - diameter of briquettes, in $\mathrm{mm}$;

1- length of briquettes, in $\mathrm{mm}$.

From these briquettes, some samples with smaller lengths were extracted in order to be used for compressive strength. To determine the breakout endurance of the materials, a universal mechanical testing instrument was used, where there were installed two compression plates, as see in Fig 2.

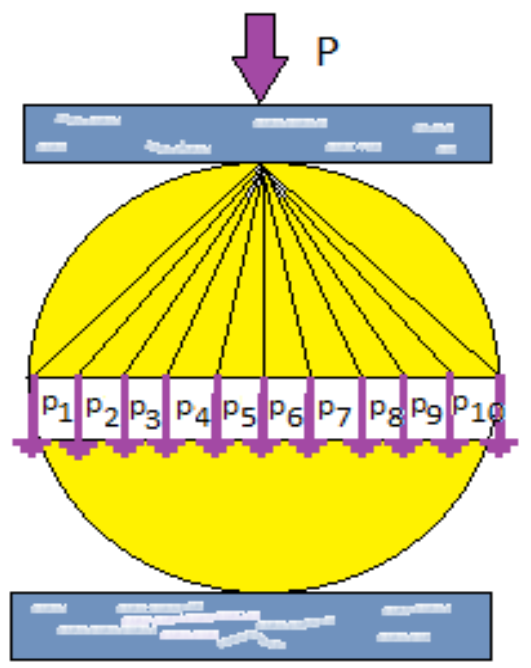

Fig. 2. Determining the compression strength of briquettes

The compressive strength of briquettes is determined as a ratio between force and area of analyzed surface (Eq.2).

$$
\sigma_{c}=\frac{F}{A}\left(N / m m^{2}\right)
$$

where:

$\sigma_{\mathrm{c}}$ is the compressive strength, in $\mathrm{N} / \mathrm{mm}^{2}$;

F- Maximum force of briquettes crash, in $\mathrm{N}$;

A -area of compressive crash surface, in $\mathrm{mm}^{2}$.

Fig 2 show that all stresses are concentrated in the middle zone of briquettes, namely the broken surface is given by diameter and length of these samples, that form a specifically area of breakage. Taking in consideration the above aspects, the compressive strength will be determined with the next relation:
$\sigma_{c}=\frac{F}{d \cdot l} \quad\left[N / m^{2}\right]$

$\sigma_{\mathrm{c}}$ is the compressive strength, in $\mathrm{N} / \mathrm{mm}^{2}$;

F- Maximum force of briquettes crash, in $\mathrm{N}$;

d- Diameter of briquettes, in $\mathrm{mm}$;

where:

$\sigma_{\mathrm{c}}$ is the compressive strength, in $\mathrm{N} / \mathrm{mm}^{2}$;

F- Maximum force of briquettes crash, in N;

d- Diameter of briquettes, in $\mathrm{mm}$;

1- length of briquettes samples, in $\mathrm{mm}$.

The installation used for determining the calorific value of the wooden biomass was the explosive burning (bomb) calorimeter type XRY-1C, produced by Shanghai Changji Geological Instrument Co., from China (Fig. 3).

Before testing the calibration of the calorimetric bomb was performed with benzoic acid with a known value of calorific value $(26463 \mathrm{~kJ} / \mathrm{kg})$. With this value of calorific value, the calorimetric coefficient noted with $k$ of calorimeter will be obtained, using the normal procedure of determination and equation of $\mathrm{CV}$ determination (Eq.3).

$$
C V=\frac{k \cdot\left(t_{f}-t_{i}\right)}{m}-\sum_{i=1}^{n} q_{i} \quad[k J / k g]
$$

where:

$\mathrm{CV}$ is calorific value, in $\mathrm{kJ} / \mathrm{kg}$;

$\mathrm{k}$ - calorific coefficient of calorimeter, in $\mathrm{kJ} /$ Celsius;

$\mathrm{t}_{\mathrm{f}}$-final temperature, in Celsius;

$\mathrm{t}_{\mathrm{i}}$-initial temperature, in Celsius;

m-mass of sample, in $\mathrm{kg}$;

$\sum_{i=1}^{n} q_{i}$ is supplementary heat release in time of testing, in $\mathrm{kJ} / \mathrm{kg}$.

Supplementary heat is given by burning nickelchromium and cotton wires and also by burning of $\mathrm{HNO}_{3}$ (usually $40 \mathrm{~J}$ ).

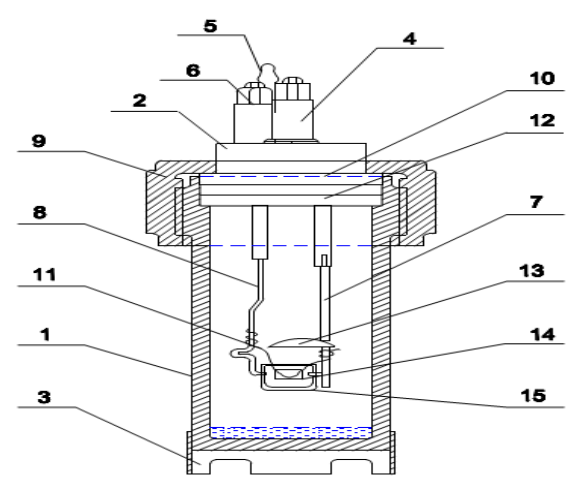

Fig. 3. Section view through calorimetric bomb

The inferior caloric power of the sunflower husk pellets is determined based on the superior caloric power, expressed in Eq.4: 
where:

$$
\mathrm{LCV}=\mathrm{HCV}-6(\mathrm{MC}+9 \mathrm{~h})[\mathrm{kJ} / \mathrm{kg}]
$$

\section{$\mathrm{LCV}$ - inferior caloric power, $\mathrm{kJ} / \mathrm{kg}$}

MC- wood moisture content of sample, $\mathrm{kJ} / \mathrm{kg}$ h- hydrogen content of the sample, estimated at 3.6\%, for the lignocellulosic materials.

The testing sample (1) is tied to the cotton thread (2) and is put in the calorimeter chamber (3). The copper nickel thread (4) is tied to the sample and the cotton thread, after which the protection covers (5) is attached. The calorimeter chamber is connected to the calorimetric bomb cover 6 through two electrodes (7) and (8), which continue with the electrical threads for calorimetric bombs coupling (9) and (10). By threading the cover, the bomb (11) is coupled to fitting (12) to the oxygen supplying unit, generating a total pressure of 30 atmospheres.

In fig. 4 the description of the process to determine the calorific power is presented, as there were presented by the computer software. The preparation of the test facility requires a series of outdoor activities, but also the introduction of data on the computer interface (such as sample weight, calorific value, etc.)

The test procedure has three main and different steps $[11,18]$ :

The first stage ("fore") has as purpose the determination of temperature variations of water in the calorimetric recipient, due to the heat exchange with the exterior before burning. During this period, usually for 5 minutes, the temperature is determined at specified intervals with the precision thermocouple.

The last reading of the temperature from the first period represents in fact the first temperature in the "main" period. The values of the temperature registered in this period are six. After registering the $6^{\text {th }}$ value the flaming/ignition of the material takes place and its reading on the menu bar ("burning time").



Fig. 4. Description of the process to determine the calorific power

The main period ("main") begins by burning (flaming) the sample and has as consequence the increase of water temperature in the calorimetric recipient, due to the burning of the pellet and heat delivery to container. The values of the temperature are indicated at one-minute periods. The values registered during this period vary according to the burning time of the fuel material in the calorimetric bomb. The number of registered temperature values may vary between $19-42$ during this period. These periods are usually equaled wit time of this period in minutes.

The final period ("after") has as purpose the determination of the average water temperature in the calorimetric recipient, due to the heat exchange with the exterior vessel after burning.

Identical to the first stage, the temperature is shown at half minute periods, for 4-5 mutes and on average there are registered $8-10$ values of the temperature variation. The last temperature value is the final temperature value and is recorded by the computer software. After that, the computer software displays the end of the test by word and position "end " by software.

For the superior calorific power, the value obtained was of $19256 \mathrm{~kJ} / \mathrm{kg}$, while for the inferior calorific power, the average value obtained was $18647 \mathrm{~kJ} / \mathrm{kg}$.

To determine the ash content of the seed husks, the general method of standardized determination was used (ASTM D2866-11, 2012). According to this method, the milled and dried material (dried to $0 \%$ moisture content) is calcined at a temperature of $750^{\circ} \mathrm{C}$ in a laboratory calibrated oven, for a period of at least 3 hours (Fig. 5).

The pellets calcination is made on a metallic melting crucible resistant to elevated temperature of 750 Celsius degrees, and the weighting was made on an analytical balance with a 3-decimal precision.

When determining the ash content, it will be taken into consideration that the sample is completely dried and the cleaned and empty melting pot weight, as in Eq.5 $[12,13]$.

$$
A_{c}=\frac{m_{a+c}-m_{c}}{m_{s+c}-m_{c}} \cdot 100 \quad[\%]
$$

where:

$\mathrm{m}_{\mathrm{a}+\mathrm{c}}$-mass of ash, considering the crucible, in $\mathrm{g}$; $\mathrm{m}_{\mathrm{s}+\mathrm{c}}-$ mas of sample considering the crucible, in $\mathrm{g}$; $\mathrm{m}_{\mathrm{c}}$ - mass of empty crucible, in $\mathrm{g}$.

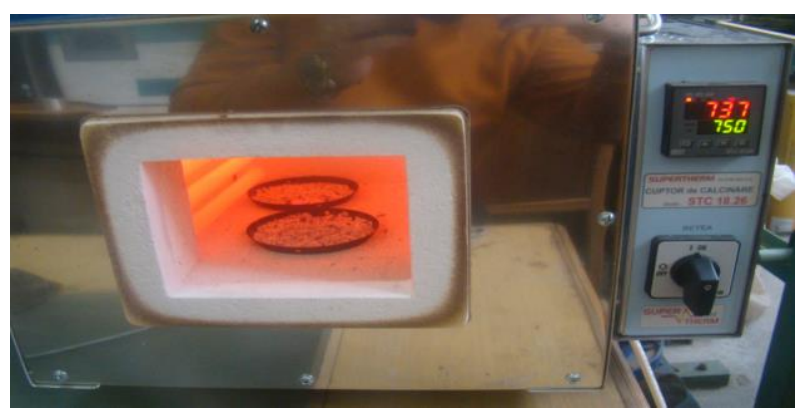

Fig. 5. Oven for determining the ash content

\section{Results and discution}

The average mean of the sunflower briquettes density is $0.9934\left(\mathrm{~g} / \mathrm{cm}^{3}\right)$ (Fig.6). Large variations could be due to the differences in compactness. 


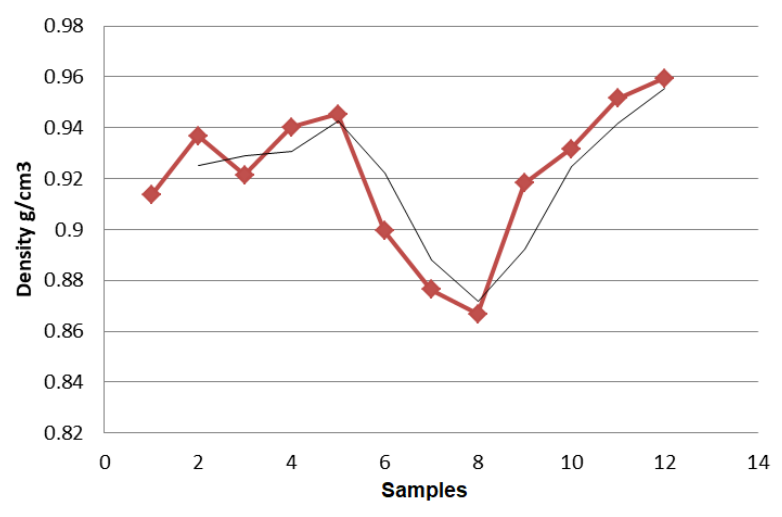

Fig. 6. The density of the briquettes

Fig.7 depicts the observed breakout endurance of briquettes, for the twelve samples taken into analysis.

The average breakout resistance or crash strength for the briquettes is $0.3-0.6 \mathrm{MPa}$.

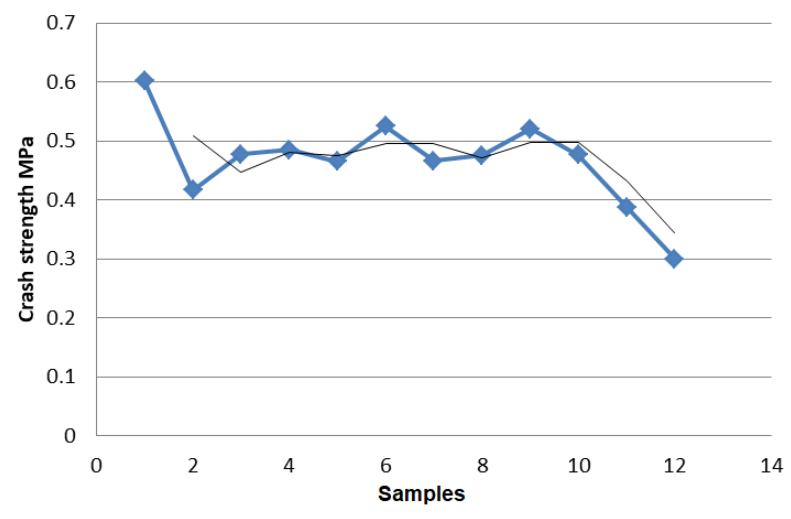

Fig. 7. Compressive strength of briquettes

In fig. 8 presented the variation of ash content, active carbon and volatile substances.

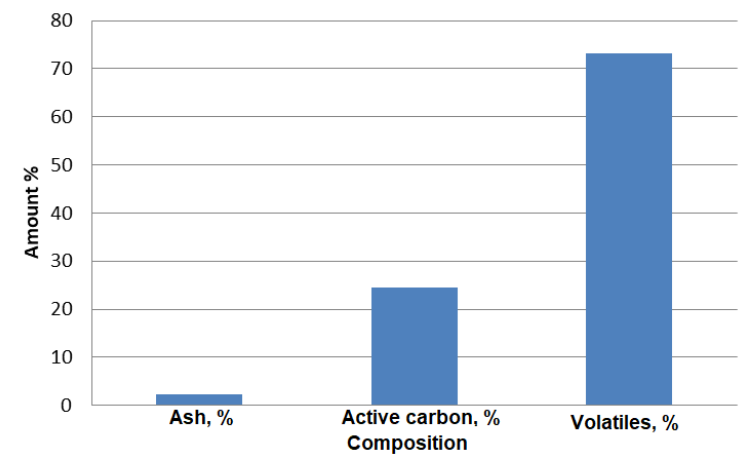

Fig. 8. Ash content, active carbon and volatile substances in the briquettes

The amount of ash contained is about $2.4 \%$, the amount of active carbon is $22.7 \%$, and the amount of volatile is $72 \%$ as determined in other research [14].

\section{Conclusions}

The sun-flower seeds shelling are a waste from sunflower oil factory. These huge wastes may be used successfully in briquettes, after their grinding, sorting and drying without using other additives. From this point of view these obtained briquettes are some natural fuel materials that can be used successfully for obtaining heat in stoves or furnaces.

The results presented in the paper have indicated that the obtained briquettes could in principle successfully replace the wooden sawdust briquettes or even the fire wood, due to the good density and the very good caloric power. The ash content of $2.4 \%$ is like some of European wooden species. The burning of briquettes obtained from sun-flower husk produce a clean energy, used for stoves or furnaces.

This kind of briquettes has not significantly influence the general properties of briquettes but it makes a major contribution to their combustion properties because of low moisture content. This is one of the main reasons (apart from economic arguments) why many briquette producers are going to do next step namely to change raw materials from wood to agricultural waste.

The crushing strength values obtained in the paper should cover the real crushing strengths, even for the most restrictive standards. Procedure of determination of breaking strength is very simple and elucidates the compactness and consistency of briquettes, thus improving the quality and properties of these products. Consequently this study has practical importance for producers and customers of briquettes.

Biomass is one of the forms of renewable sources which may be converted in solid, liquid and gaseous energetic fuel and which may generate energy as heat by its burning, as well as electrical energy by conversion processes.

Presently the biomass contributes with approximately $12 \%$ to the production of primary energy in the world, and in the countries in developing process it covers 40 $50 \%$ of the necessary of energy. The Biomass is the alternative source that, according to contributed with $7 \%$ from the energy produced in the world. Presently, the use of renewable fuel materials such as wooden wastes for producing biofuels increases the chances of biomass in the availability level on the energetic market.

Biomass is environmentally friendly and a neutral energy against the emissions of carbon dioxide. The carbon dioxide is absorbed by the plants during the growing process and forms a closed circuit, because the quantity of carbon dioxide which was absorbed by the plants during the growing process will be equal to the one which was eliminated during the complete burning process.

\section{Acknowledgement}

We wish to acknowledge stuff of Transilvania University of Brasov, Project nr. 8063/2.07.2018 (The program of quality evaluation of briquettes from sunflower seed husk).

\section{References}

1. T. Banta, R. De Leona, Parametric study of rice husk torrefaction for the development of sustainable 
solid fuel International Journal of Smart Grid and Clean Energy Vol 7, No 3, pp. 207-217 (2018)

2. A.V. Bridgwater, Review of Fast Pyrolysis of Biomass and Product Upgrading, Biomass bioenergy, vol. 38, pp. 68-94 (2012)

3. J.P. Boutin, G. Gervasoni, R. Help, K. Seyboth, P. Lamers, M. Ratton, et al Altrnative energy sources in Transition Countries. The case of Bio-energy in Ukraine, Environmental Engineering and Management Journal, vol. 6, nr.1, pp.3-11 (2007)

4. A. Demirbas Resource Facilities and Biomass Conversion Processing for Fuels and Chemicals, Energy Conversion Management, vol. 42, nr. 11, pp. 1357-1378, (2011)

5. A.M. Garcia, B.M.J. Barcia, J.A. Hernandez Preparation of active Carbon from a Comercial Holm-Oak Charcoal: Study of Micro and Mesoporosity, Journal Wood Science and Technology, vol. 37, nr. 5, pp. $499-509$ (2008)

6. D. Gavrilescu Energy from biomass in pulp and paper, Environmental Engineering and Management Journal, vol. 7(5), pp.537-546, (2008)

7. M. Gavrilescu Biomass Power for Energy and Sustainable Development, Environmental Engineering and Management Journal, vol. 7(5), pp.617-640, (2008)

8. N. Kaliyan, R.V. Morey Factors Affecting Strength and Durability of Densified Biomass Product, Biomass Bioenerg, vol. 33, nr. 3, pp. 379-359, (2009)

9. T. Kuhlman, V. Diego, E. Koomen Exploring the potential of reed as a bioenergy crop in the Netherlands, Biomass Bioenergy, vol. 55, pp.41-52, (2013)

10. J. Lako, J. Hancsok, T. Yuzhakova, G. Marton, A. Utsai, A. Redey, Biomass and Bioenergy, vol. 40, pp. 63-73, (2012)
11. A. Lunguleasa Compaction coefficient of wooden briquettes used as renewable fuel, Environmental Engineering and Management Journal, vol.10, nr. 9, pp.1263-1268, (2011)

12. C. Okello, S. Pindozzi, S. Faugno, L. Boccia Bioenergy potential of agricultural and forest residues in Uganda, Biomass Bioenergy, vol. 56, pp. 515-525, (2013)

13. N. A. Pambudi, K. Itaoka, A. Chapman, N. D. Hoa, N. Yamakawa Biomass energy in Japan: Current status and future potential, International Journal of Smart Grid and Clean Energy, vol. 6, no. 2, pp. 119126 (2017)

14. B. Popescu, L. Șenilă, C. Vărăticeanu, G. Șimon Cellulosic bioethanol from sunflower seed hulls-a renewable energy source, Studia UBB Ambientium, vol. 1-2, pp.105-110, (2013)

15. J. Swithenbank, Q. Chen, X. Zhang, V. Sharifi, M. Pourkashamiani Wood would burn, Biomass and bioenergy, vol.3, (2011)

16. J. Tanchuling, R. De Leon Solid fuel characterization of torrefied coconut shells in an oxidative environment, International Journal of Smart Grid and Clean Energy, vol. 7, no. 2, pp. 145151 (2018)

17. O. Teuch A. Hofeanuer, F. Troger, J. From Basic properties of specific wood based materials carbonised in a nitrogen atmosphere, Wood Science Technology Journal, vol.38, nr.3, pp.323-333, (2004)

18. V.K. Verna, S. Bram, J. de Rucky Small Scale Biomass Systems: Standards, Quality, Labeling and Market Driving Factors-An Outlook Biomass Bioenerg, vol.33, nr. 10, pp. 1393-1402, (2009) 